\title{
FINITE ELEMENT ANALYSIS OF ARCH DAM
}

\author{
Binol Varghese', Arya Saju², Simi John \\ ${ }^{1} U G$ Scholar, Mar Athanasius College of Engineering, Kothamangalam, India \\ ${ }^{2} U G$ Scholar, Mar Athanasius College of Engineering, Kothamangalam, India \\ ${ }^{3} U G$ Scholar, Mar Athanasius College of Engineering, Kothamangalam, India
}

\begin{abstract}
The main objective of this paper is to perform structural analysis of arch dam using finite element method. Since the dam possesses complex double curvature shell structure analysis using conventional structural analysis method $s$ is not preferable. Therefore opted finite element method opted. Among the many FEM packages that are available, ANSYS is a package that makes analysis of complex structures possible with least errors. The paper mainly focuses on the location of major stress concentration points and deflections of the dam.
\end{abstract}

Keywords: arch dam, finite element method, von Mises stress

\section{INTRODUCTION}

\subsection{Types of Arch Dam}

The definition for an arch dam by ICOLD includes all curved dams, where the base-thickness is less than 0.6 times the height. Mainly arch dams are grouped into:

$\begin{array}{ll}\text { 1. } & \text { Constant radius } \\ \text { 2. } & \text { Variable radius } \\ \text { 3. } & \text { Constant angle } \\ \text { 4. } & \text { Multiple arch } \\ \text { 5. } & \text { Cupola (shell) } \\ \text { 6. } & \text { Arch gravity } \\ \text { 7. } & \text { Mixed type }\end{array}$

\subsection{Methods of Analysis of Arch Dam}

The conventional methods adopted for the analysis of all types of arch dams are cylinder theory, method of independent arches, trial load and model analysis which are found to be of limitations for multiple radius arch dams of height greater than $100 \mathrm{~m}$. Later, accurate methods are necessitated by eliminating many assumptions made in the traditional methods for ensuring safety and economy which led to numerical methods such as finite difference, finite element and boundary element for arch dams. Of these, finite element is the most effective method for handling a continuum like arch dam since it gives a more realistic stress distribution and more flexibility with regard to geometry and boundary conditions than other methods. Hence, a critical study on how the finite element method resolves the complexity in the case of an arch dam of varying geometry is presented here.

Main methods of analysis of arch dam are:

1. Preliminary methods

- Thin cylinder theory

- Thick cylinder theory

- Elastic theory

- Active arch method

- Cain's method
- U.S.B.R. criteria

- Institution of Engineers, London

- R. S. Varshney's equations

2. Elaborate methods

- Inclined arch method

- Tolke method

3. Trial load analysis

- USBR

4. More elaborate methods

- Finite element method

- Shell analysis method

- Three-dimensional elastic solution

- Finite difference method

- Three-dimensional electric analogue

- Dynamic relaxation of three-dimensional elastic solution

5. Experimental method

- Model studies

According to CBIP publication the methods of analysis commonly adopted are discussed below.

\subsubsection{Cylinder Theory}

The simplest and the earliest of the methods available for the design of an arch dam is the cylinder theory. In this theory, the stress in an arch dam is assumed to be the same as in a cylindrical ring of equal external radius. The arch thickness is calculated by the thin cylinder formula. The cylinder theory does not allow for the discontinuity of the arch at the abutment and is, therefore, highly approximate. The use of cylinder theory has been restricted to dams less than $30 \mathrm{~m}$ in height located in narrow valleys. A low value of permissible stress in concrete, usually about 60 per cent of the permissible stress, issued to allow for the highly approximate nature of the formula. The cylinder theory is only of historical importance now.

\subsubsection{Method of Independent Arches}

This method considers the dam to be made up of a series of 
arches with no interaction between them. It is assumed that all horizontal water loads are carried horizontally to the arch abutments by arch action and that only the dead load weights plus the vertical water loads in the case of sloping upstream face are carried vertically to the foundation by cantilever action. If the canyon is relatively regular and narrow and the dam is of low height so that a symmetrical thin structure with large central angle can be adopted this method may give reasonably satisfactory results.

Practically the water load is transferred to the foundation and abutments, both by horizontal arch action and vertical cantilever action. The vertical cantilevers are restrained at the foundation and must bend under their share of water load until their deflected positions coincide with the deflected positions of horizontal arch elements. The theory that the entire water load is carried horizontally to the abutments is therefore, incorrect and the design that ignores vertical cantilever action can seldom be considered as wholly satisfactory.

\subsubsection{Arch Cantilever (Trial Load) Method}

The most commonly accepted method of analysing arch dams assumes that the horizontal water load is divided between the arches and cantilevers so that the calculated arch and cantilever deflections are equal at all conjugate points in all parts of the structure. Because the required agreement of all deformations is obtained by estimating various load distributions and computing the resulting movements until the specified conditions are fulfilled, the procedure is logically called trial-load method.

Trial load analyses may be classified into the following types depending on their relative accuracy and corresponding complexity.

\subsubsection{Crown Cantilever Analysis}

Crown-cantilever analysis consists of an adjustment of radial deflections at the crown cantilever with the corresponding deflections at the crowns of arches. This type of analysis assumes a uniform distribution of radial load from the crowns of arches to their abutments and neglects the effects of tangential shear and twist. While the results obtained from this analysis are rather crude, it has the advantage of very short time to complete the analysis. If used with judgment, it is an effective tool for appraisal studies.

\subsubsection{Radial Deflection Analysis}

A radial deflection analysis is one in which radial deflection agreement is obtained at arch quarter points with several representative cantilevers by an adjustment of radial loads between these structural elements. With the use of this type of analysis, loads may be varied between the crowns and abutments of arches, thus producing a more realistic distribution of load in the dam. A radial deflection analysis may be used for a feasibility study.

\subsubsection{Complete Trial Load Analysis}

A complete trial-load analysis is carried out by properly dividing the radial, tangential and twists loads between the arch and cantilever elements until-agreement is reached for arch of the three axial and three rotational movements for each arch cantilever node point. The accuracy of this analysis is limited only by the exactness of the basic assumptions, the number of vertical and horizontal elements chosen, and the magnitude of the error permitted in the slope and deflection adjustments. In view of the comprehensive and involved nature of the complete trial-load analysis, it is desirable that preliminary studies of tentative dams are first carried out by simplified methods; crown cantilever analysis and radial deflection analysis, to obtain a dam; proposed for complete trial load analysis, which is most suitable for the given site and whose dimensions are as close to the final as practicable.

\subsubsection{D Finite Element Analysis}

The deformations and stresses in an arch dam can alternatively be determined by three-dimensional finite element analysis which provides a more accurate solution of the problem and is being increasingly used. The finite elements can be extended to include the foundation and appropriate moduli values can be used whether the foundation is homogeneous or not, which avoids the use of Vogt's approximate assumptions on contact area and distribution of loading. According to Zienkewicz, the trial load method gives comparable results with 3D finite element analysis only for the simple cylindrical shapes. In doubly curved dams of modern type, the trial load assumptions are dubious and recent comparisons show that, in fact, considerable differences exist between its results and those of full 3D treatment.

\subsection{Finite Element Formulation}

\subsubsection{Finite Element Analysis}

The stress analysis in the fields of civil, mechanical and aerospace engineering, naval architecture, offshore engineering and nuclear engineering is invariably complex, and for many of the problems, it is extremely difficult and tedious to obtain analytic solutions. In these situations, engineers' usually resort to numerical methods to solve the problems. An analytic solution is a mathematical expression that gives the value of the field variable at any location in the body. For problems involving complex boundary conditions, it is difficult and in many cases intractable to obtain analytical solutions that satisfies the governing differential or gives the extreme value to the governing functional. The three numerical methods that provide approximate solutions are functional approximation, finite difference method and finite element method.

\subsubsection{Functional Approximation}

A set of independent functions satisfying the boundary conditions is chosen and a linear combination of a finite number of them is taken to approximately specify the field variable at any point. The unknown parameter that combines the functions is found out at such a way to achieve at best the field condition, which is represented through variation formulation. Classical methods such as Rayleigh Ritz and 
Galerkin are based on the functional approximation but vary in their procedure for evaluating the unknown parameters. The concept of Rayleigh Ritz method, i.e. representing the variation of the field variable by trial function and finding the unknown parameters through minimization of potential energy, are well exploited in the finite element method.

\subsubsection{Finite Element Method}

Finite element method is an essential and powerful tool for solving structural problems not only in the marine field but also in the design of most industrial products and even in non-structural fields. FEM can be used for a wide variety of problems in linear and nonlinear solid mechanics, dynamics, and submarines structural stability problems, in accordance with the development of computer technology and its popularization. The conventional method in solving stress and deformation problems is an analytical one using theories of beams, columns and plates, etc. Hence its application is restricted to most simple structures and loads.

In the finite element method, the solution region is considered as built up of many small, interconnected sub regions called finite elements. Since it is very difficult to find the exact response of complicated structure under specified loading conditions, the structure is approximated as composed of several pieces in the finite element model.

\subsection{Basic Steps in Finite Element Analysis}

The finite element analysis method requires the following major steps:

1. Discretization of the domain into a finite number of subdomains (element).

2. Selection of interpolation functions.

3. Development of the element matrix for the subdomain (element)

4. Assembly of the element matrices for each subdomain to obtain the global matrix for the entire domain.

5. Imposition of the boundary conditions.

6. Solution of equations.

\subsubsection{Idealization}

The process of converting the actual 3D problem into structure, which is simple and easy to handle is called idealization.

\subsubsection{Discretization and Preprocessing of Finite}

\section{Element Model}

As the first step in the analysis, the given solid or structure is to be discretized into finite elements. This step requires knowledge of the physical behavior of the solid or structure to decide on the type of analysis and elements to be used to arrive at the finite element model. In addition, decision has to be made in the shape of elements to be used (higher or lower order elements), the number of elements and the pattern of the finite element mesh.
After the discretization, the nodes are numbered keeping in view the minimum bandwidth. Graphics based preprocessors are available in many package program to automatically generate the mesh and number the nodes and elements.

If a structure such as a cylindrical submarine shell, together with loads and boundary conditions, then finite elements can be used to determine the deformations and stresses in the structure. Finite elements can also be applied to analyze dynamic response, heat conduction, fluid flow and other phenomena. Today, various commercial finite element packages have started to include some optimization capability in their codes.

\subsubsection{Formulation of Element Stiffness Matrix [K]}

The stiffness matrix $[\mathrm{K}]$ of an element is calculated using the equation

$$
[\mathrm{K}]=\int[\mathrm{B}] \mathrm{T}[\mathrm{C}][\mathrm{B}] \mathrm{dV}
$$

Where,

$[\mathrm{C}]=$ Constitutive matrix

$[\mathrm{B}]=$ Strain displacement matrix

\subsubsection{Formulation of Load Vector [P]}

Based on the type of loading, equivalent joint load and moment at each node are calculated and the load vector is formulated.

\subsubsection{Assembly of Stiffness Matrices}

The stiffness matrix for each element is calculated and they are diagonally combined at their respective nodes to get the assembled $[\mathrm{K}]$ matrix.

\subsubsection{Application of Boundary Condition}

To eliminate rigid body motion we must impose boundary conditions. For example, fixed boundary condition, clamped boundary condition and simply supported condition etc.

\subsubsection{Computation of Deformation}

By applying equations of equilibrium, the deformation at each node is calculated using equation

$$
\begin{gathered}
{[\mathrm{K}][\mathrm{D}]=[\mathrm{P}]} \\
{[\mathrm{D}]=[\mathrm{K}]-1[\mathrm{P}]}
\end{gathered}
$$

Where $[\mathrm{D}]=$ Deflection matrix

\subsubsection{Computation of Stresses and Post Processing of} Results 
The stresses at any point in the element can be computed using the equation,

$$
\{\sigma\}=[\mathrm{C}][\mathrm{B}][\mathrm{D}]
$$

Graphics based post-processing are widely available in all packages programs that would enable plotting of the deflected shape of the structure, stress contours, variation of a particular type of stress across a given section etc.

\section{General Comments on Dividing into Elements}

When dividing area into triangles avoid large space ratios. Aspect ratio is defined as the ratio of maximum to minimum characteristics dimensions. The best elements are those that approach an equilateral triangular configuration. Such configurations are not usually possible. Coarse measures are recommended for initial trials to check data and reasonableness of results. Increasing the number of elements in those regions where stress variants are high should give better results. This is called convergence. Convergence should be increasing successively while increasing the number of elements in finite element meshes.

\section{Convergence Requirements}

The finite element method provides a numerical solution to a complex problem. It may therefore be expected that the solution must converge to the exact solution under certain circumstances. It can be seen that the displacement formulation of the method leads to the upper bound to the correct result. This would be achieved by satisfying the three conditions.

1. The displacement function must be continuous within the element. Choosing polynomials for the displacement model can easily satisfy this condition.

2. The displacement function must be capable of representing rigid body displacement of the element. When the nodes are given such displacement corresponding to a rigid body motion, the element should not experience any strain and hence leads to zero nodal forces. The constant terms in the polynomials used for the displacements modes would usually ensure this condition.

3. The displacement function must be capable of representing constant strain states within the element. When the body or structure is divided into smaller and smaller elements, as these elements approach infinitesimal size, the strains in each element also approach constant values.

4. The displacement must be compatible between adjacent elements. That is when the elements deforms there must not be any discontinuity between elements, that is elements must not overlap or separate.

5. Elements which satisfy all the three converge requirements and compatibility conditions are called compatible or compatible elements. And elements which violate the compatibility requirements are known as incompatible elements.

\section{Static Analysis}

Linear static analysis is performed to predict the response of the structure under prescribed boundary conditions and time independent applied loads, when linear response behavior can be assumed with reasonable accuracy. The desired response quantities are generally stress, strain displacements, energy and reactions. In general, applied loads include prescribed forces or moments at nodes, uniform or non-uniform pressures applied on the faces of elements as well as gravity and centrifugal force (body forces) and loading due to thermal expansion or contraction. The boundary conditions are specified displacement values (zero or non-zero) at prescribed nodes or they may be including coupled multi point constraint equations, coupled displacements or rigid limits. The basic equation for linear static analysis may be written in the form:

$$
[\mathrm{K}][\mathrm{D}]=\{\mathrm{P}\}
$$

Where $[\mathrm{K}]=$ linear stiffness matrix of the structure (known) $[\mathrm{D}]=$ nodal displacement vector (unknown)

$\{\mathrm{P}\}=$ static load vector

The number and intensity of domestic and international terrorist activities, including the September 11, 2001 attack on World Trade Center towers in New York, have heightened our concerns towards the safety of our infrastructure systems. Terrorists attack targets where human casualties and economic consequences are likely to be substantial. Transportation infrastructures have been considered attractive targets because of their accessibility and potential impacts on human lives and economic activity.

Bridges are an integral part of national highway system. Military assaults, terrorist attacks and accidental explosions may cause serious damage to bridges. As a result, engineers and transportation office workers are more active in the construction of strong bridges to withstand potential blast attacks. Explosion accident analyses, blast-resistant design and anti-terrorist and military weapon design have become more important areas. Damage effect analyses and assessments of bridges under blast loading are very important in these areas. With the rapid development of computer hardware over the last decades, detailed numerical simulations of explosive events in personal computers have become possible.

Loads imposed on highway bridge components during a blast loading event can exceed those for which bridge components are currently being designed. In some cases, the loads can be in the opposite direction of the conventional design loads. Consequently, highway bridges designed using current design codes may suffer severe damages even from a relatively small sizes explosion.

\subsection{Process of Finite Element Analysis}




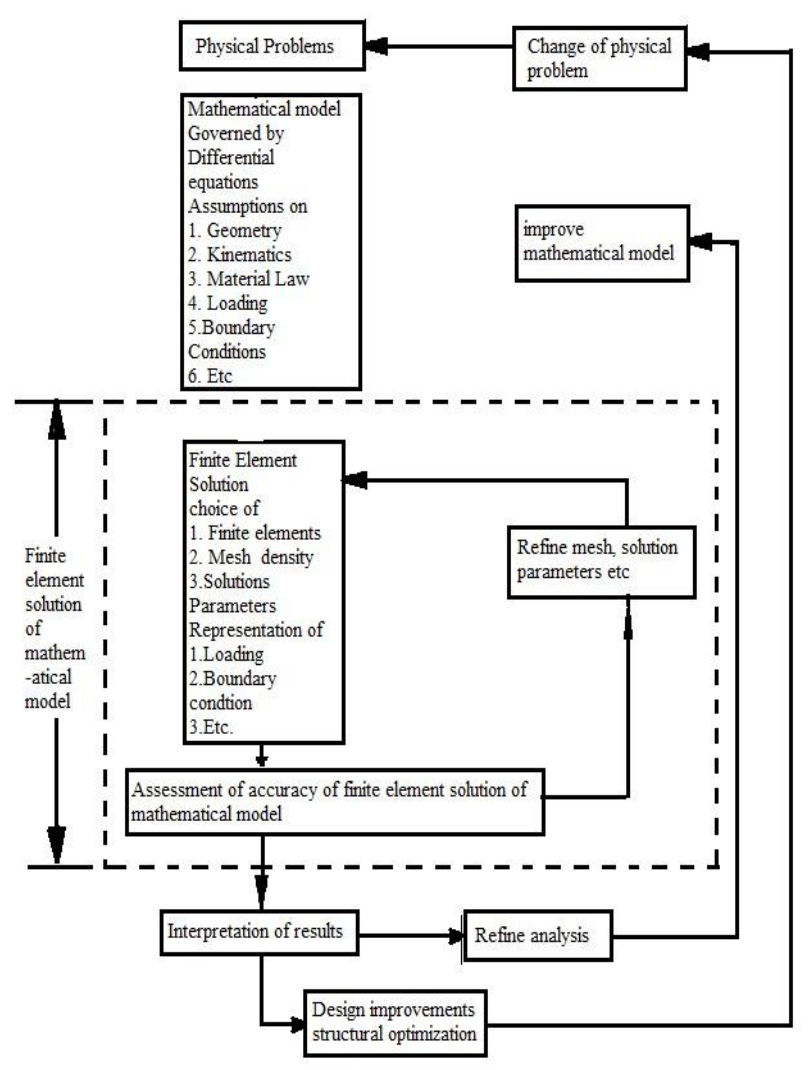

Fig 1.1 Process of finite element analysis

\subsubsection{Need of Finite Element Method}

Earlier, finite element method with two dimensional analysis using plane stress and plane strain as well as shell theory that actually approximates three-dimensional problem by two-dimensional one were used. Though it gives good results for a thin arch dam, thick arch dam requires a rigorous three dimensional analysis. There is an urgent need for considering the effect of variable curvature by approximating the geometry with higher order polynomials incorporating more nodal points at element level itself while modeling.

The available literature and software show that the hydrostatic pressure on the curved surface is seen approximated as normal to the surface by means of certain global coefficients to the horizontal pressure on vertical surface. In fact, the magnitude as well as direction will be varying at each point, i.e. water pressure will be normal to the curved surface, horizontal and vertical extrados, with components in the three directions. In the finite element method, water pressure needs to be considered more accurately as actual distributed surface forces on each element by direction cosines and numerical integration. Similarly the silt pressure, uplift and dynamic effect of the reservoir water also will have to be considered at element level itself.

\subsubsection{Merits of Finite Element Method}

The following are the advantages of finite element method. $\square$ The method can effectively be applied to cater to irregular boundary.

$\square$ It can take care of any type of complicated boundary.

$\square$ Material like homogeneous, heterogeneous, anisotropic, isotropic, orthotropic can be treated without much difficulty.

$\square$ Any type of material can be handled.

$\square$ Structures with complicated geometry can be analyzed by using finite element method.

$\square$ Nonlinear and dynamic analysis can be done.

\subsubsection{Boundary Conditions}

Boundary conditions either define the loads that act on the structure (force or Neumann boundary conditions), or describe the way in which the structure is supported (displacement boundary conditions). Both types of boundary conditions often involve simplifications of actual structural situation, either to reduce the model size by replacing structure with boundary conditions or because the real state of loading and support is known imperfectly. A consistent set of boundary conditions is required for a unique mathematical solution of the finite element equations.

The boundary conditions used is: Fixed - fixed (UX, UY, UZ and ROTX, ROTY, ROTZ are restraint at the nodes).

\subsection{ANSYS v12.0}

ANSYS offers a comprehensive range of engineering simulation solution sets providing access to virtually any field of engineering simulation that a design process requires. Companies in a wide variety of industries use ANSYS software. The structural integrity of any building is only as good as its individual parts. The way those parts fit together along with the choice of materials and its specific site all contribute to how the building will perform under normal or extreme conditions. Civil engineers need to integrate this vast number of pieces into their building designs; furthermore, they need to comply with increasingly demanding safety and government regulations. At the same time, the general public is demanding environmentally conscious designs. ANSYS simulation software gives designers the ability to assess the influence of this range of variables in a virtual environment. Thus, engineers can advance through the design and materials selection process quickly and efficiently. ANSYS tools guide the user through coupled rock and soil mechanics analysis; material-specific maximum load assumptions; linear, nonlinear, static and dynamic analyses; sensitivity and parametric studies; and other related work - which together provide significant insight into design behavior that would be difficult with single analysis runs. Through visualizing the effect of a wide range of variables, engineers can narrow the scope of field investigations, save considerable time and cost on projects, and move more quickly to the groundbreaking stage. The advanced capabilities of ANSYS software create a powerful tool for civil engineering projects as diverse as high-rise buildings, bridges, dams, tunnels and stadiums. By testing materials and experimenting with design in a virtual environment, engineers and designers can analyze safety, strength, comfort and environmental considerations. The 
result is cost-effective and innovative design.

\subsubsection{Merits of ANSYS}

The merits of analysis of an arch dam by ANSYS are:

- The cost of a computer run will be far economical than a corresponding experimental investigation.

- Computational investigations will be of remarkable speed and designer can study the implications of different configurations faster and can choose the optimum design from among several possible designs.

- Computer solution gives detailed and complete information for all the relevant variables throughout the domain of interest.

- Realistic conditions can be simulated in the theoretical calculations and convergence achieved faster.

ANSYS is general purpose software used for different type of structural analysis and also for various engineering fields. It can be used to solve a wide variety of problems such as structural, mechanical, heat transfer, and fluid dynamics problems as well as problems of other disciplines. It provides powerful pre and post processing tools for mesh generation from any geometry source, to produce almost any element type, for usually any application. ANSYS provides a wide variety of elements that can be used for 1-D, 2-D and 3-D problems, for the analysis purposes. So it becomes necessary to find the right element to do the right type of analysis. In general, a finite element solution may be broken into the following three stages. This is a general guideline that can be used for setting up any finite element analysis.

1. Preprocessing: defining the problem; the major steps in Preprocessing are given below:

- Define key points/lines/areas/volumes.

- Define element type and material/geometric properties.

- $\quad$ Mesh lines/areas/volumes as required.

The amount of detail required will depend on the dimensionality of the analysis. (i.e. 1D, 2D, 3D, axi-symmetric).

2. Solution: assigning loads, constraints and solving; here specify the loads (points or pressure), constraints (translational and rotational) and finally solve the resulting set of equations.

3. Post processing: further processing and viewing of the results; in this stage one may view:

- $\quad$ Lists of nodal displacements.

- $\quad$ Element forces and moments.

- Deflection plots.

- Stress contour diagrams.

\subsection{Von Mises Stress}

A structure can have two kinds of failure, material failure and form failure. In material failure, the stresses in the structure exceed the safe limit resulting in the formation of cracks which cause failure. In form failure, though the stresses may not exceed safe value, the structure may not be able to maintain the original form and here the structure does not physically fail but may deform to some other shape due to intolerable external disturbances. Form failure depends on geometry and loading of the structure. It occurs when conditions of loading are such that compressive stress gets introduced in the structure. To understand the cause of failure, one needs to know not only the equilibrium of the structures but also the nature of equilibrium.

Von Mises stress is a misnomer. It refers to a theory called the Von Mises-Hencky criterion. In an elastic body that is subject to a system of loads in 3 dimensions, a complex 3 dimensional system of stresses is developed (as you might imagine). That is, at any point within the body there are stresses acting in different directions, and the direction and magnitude of stresses changes from point to point. The von Mises criterion is a formula for calculating whether the stress combination at a given point cause failure.

There are three "principal stresses" that can be calculated at any point, acting in the $\mathrm{x}, \mathrm{y}$ and $\mathrm{z}$ directions. The $\mathrm{x}, \mathrm{y}$ and $\mathrm{z}$ directions are the "principal axes" for the point and their orientation changes from point to point, but that is a technical issue. Von Mises found that, even though none of the principal stresses exceeds the yield stress of the material, it is possible for yielding to result from the combination of stresses. The von Mises criterion is a formula for combining these 3 stresses into an equivalent stress, which is then compared to the yield stress of the material. The yield stress is a known property of the material, and is usually considered to be the failure stress. The equivalent stress is often called the "von Mises stress" as a shorthand description. It is not really a stress, but a number that is used as an index. If the "von Mises stress" exceeds the yield stress, then the material is considered to be at the failure condition.

In a broad sense the result of changing the theory of failure from the maximum shear stress to the maximum distortion energy (von Mises theory) - is a more accurate analysis which leads to calculated stresses closer to the real developed stresses. This allows for a less conservative design and a savings in material and weight.

\subsection{Element Used}

The element used for the modeling is Solid Shell 190 (SOLSH190).

\subsubsection{Solid Shell (SOLSH190)}

SOLSH190 is a eight node hexahedral element used for simulating shell structures with a wide range of thickness (from thin to moderately thick). The element possesses the continuum solid element topology and features eight-node connectivity with six degrees of freedom at each node: translations in the nodal $\mathrm{x}, \mathrm{y}$, and $\mathrm{z}$ directions. The element 
has plasticity, hyper elasticity, stress stiffening, creep, large deflection, and large strain capabilities.

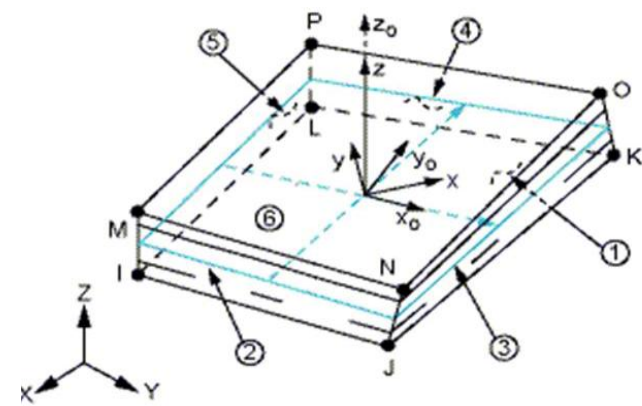

Fig 1.2 Solid Shell

\section{MODELLING}

\subsection{Basic Assumptions}

The actual structure consists of horizontal inspection galleries and vertical shafts connecting them. This structure are not considered here while modeling and analysis. The dam section actually consists of steel reinforcements to support the inspection galleries and shafts which is neglected since in this paper, does not consider inspection galleries and shafts.

\subsubsection{Concrete}

Concrete is considered homogeneous, isotropic and linearly elastic. Though, this assumption is not valid in the case of ordinary reinforced concrete structures, for a massive structure like a dam the error introduced is negligible under working loads.

The material properties are taken as follows.

- Modulus of elasticity: $2.1 \times 10^{7} \mathrm{kN} / \mathrm{m}^{2}$

- Coefficient of thermal expansion: $5.5 \times 10^{6} /{ }^{\circ} \mathrm{F}$

- Poisson's ratio: 0.20

- Unit weight: $24 \mathrm{kN} / \mathrm{m}^{3}$

- Compressive strength: $28 \times 10^{3} \mathrm{kN} / \mathrm{m}^{2}$

\subsubsection{Rock}

It is assumed that the foundations are homogeneous, isotropic and elastic with the following rock characteristics.

- Modulus of elasticity: $2.1 \times 10^{7} \mathrm{kN} / \mathrm{m}^{2}$

- Poisson's ratio: 0.20

Since the two ends and the bottom of the dam comprises completely of rigid rocks, assuming fixed boundary conditions.

\subsubsection{Stresses}

The actual maximum allowable working stresses for the concrete in the case of normal loads are $7000 \mathrm{kN} / \mathrm{m}^{2}$ for compressive stresses and $700 \mathrm{kN} / \mathrm{m}^{2}$ for tensile stresses.

- Loads

- Dead load (concrete) : $24 \mathrm{kN} / \mathrm{m}^{3}$

- Dead load (water) : $10 \mathrm{kN} / \mathrm{m}^{3}$
- $\quad$ Maximum water level : $156.50 \mathrm{~m}$

- $\quad$ Silt pressure : $12.5 \mathrm{kN} / \mathrm{m}^{3}$

- $\quad$ Maximum silt level : $77.5 \mathrm{~m}$

- Temperature

- $\quad$ Air (max. monthly av.) : $26.7^{\circ} \mathrm{C}$

- Water at surface: $21.11^{\circ} \mathrm{C}$

- Water at bottom: $15.5^{\circ} \mathrm{C}$

\subsection{Global Coordinates of the Dam}

The geometry of the arch dam is modeled by inputting the global coordinates of 80 points of the dam as shown below.

Table 2.1.Global coordinates

\begin{tabular}{|c|c|c|c|}
\hline Node & $X$ & $Y$ & $Z$ \\
\hline 1 & 18.8976 & -10.9728 & 0 \\
\hline 2 & 17.0688 & 5.4864 & 0 \\
\hline 3 & 11.5824 & -13.4112 & 0 \\
\hline 4 & 10.9728 & 4.2672 & 0 \\
\hline 5 & 5.4864 & -14.6304 & 0 \\
\hline 6 & 4.8768 & 4.2672 & 0 \\
\hline 7 & 0 & -14.6304 & 0 \\
\hline 8 & 0 & 3.6576 & 0 \\
\hline 9 & -4.8768 & -13.4112 & 0 \\
\hline 10 & -3.0480 & 4.2672 & 0 \\
\hline 11 & -10.9728 & -10.9728 & 0 \\
\hline 12 & -6.7056 & 5.4864 & 0 \\
\hline 13 & -17.0688 & -8.5344 & 0 \\
\hline 14 & -10.3632 & 7.3152 & 0 \\
\hline 15 & -21.9456 & -6.7056 & 0 \\
\hline 16 & -12.192 & 8.5344 & 0 \\
\hline 17 & 66.0832 & 8.5344 & 39.624 \\
\hline 18 & 42.6720 & 28.0416 & 39.624 \\
\hline 19 & 37.7952 & -6.096 & 39.624 \\
\hline 20 & 28.0416 & 12.192 & 39.624 \\
\hline 21 & 22.5552 & -14.6304 & 39.624 \\
\hline 22 & 15.2400 & 4.2672 & 39.624 \\
\hline 23 & 0 & -17.6784 & 39.624 \\
\hline 24 & 0 & 0.6096 & 39.624 \\
\hline 25 & -18.8976 & -14.6304 & 39.624 \\
\hline 26 & -12.192 & 2.4384 & 39.624 \\
\hline 27 & -34.7472 & -9.144 & 39.624 \\
\hline 28 & -24.484 & 9.144 & 39.624 \\
\hline 29 & -51.2064 & 0 & 39.624 \\
\hline 30 & -35.9664 & 18.288 & 39.624 \\
\hline 31 & -60.9600 & 10.9728 & 39.624 \\
\hline 32 & -43.8912 & 27.432 & 39.624 \\
\hline 33 & 85.344 & 23.1648 & 79.248 \\
\hline 34 & 71.9328 & 37.7952 & 79.248 \\
\hline 35 & 62.1792 & 4.8768 & 79.248 \\
\hline 36 & 51.2064 & 19.5072 & 79.248 \\
\hline 37 & 32.9184 & -9.7536 & 79.248 \\
\hline 38 & 26.8224 & 4.8768 & 79.248 \\
\hline 39 & 0 & -15.8496 & 79.248 \\
\hline 40 & 0 & 0 & 79.248 \\
\hline 41 & -26.8224 & -12.192 & 79.248 \\
\hline 42 & -20.1168 & 3.048 & 79.248 \\
\hline 43 & -48.1584 & -2.4384 & 79.248 \\
\hline
\end{tabular}




\begin{tabular}{|c|c|c|c|}
\hline 44 & -41.4528 & 12.192 & 79.248 \\
\hline 45 & -69.4944 & 9.7536 & 79.248 \\
\hline 46 & -57.9120 & 24.384 & 79.248 \\
\hline 47 & -85.344 & 23.1648 & 79.248 \\
\hline 48 & -70.7136 & 36.576 & 79.248 \\
\hline 49 & 106.0700 & 33.528 & 118.872 \\
\hline 50 & 97.5360 & 45.72 & 118.872 \\
\hline 51 & 75.5904 & 11.5824 & 118.872 \\
\hline 52 & 67.0560 & 23.1648 & 118.872 \\
\hline 53 & 38.4048 & -3.048 & 118.872 \\
\hline 54 & 35.3568 & 8.5344 & 118.872 \\
\hline 55 & 0 & -9.144 & 118.872 \\
\hline 56 & 0 & 3.048 & 118.872 \\
\hline 57 & -41.4528 & -3.048 & 118.872 \\
\hline 58 & -37.7952 & 9.7536 & 118.872 \\
\hline 59 & -81.6864 & 15.24 & 118.872 \\
\hline 60 & -74.3712 & 26.2128 & 118.872 \\
\hline 61 & -115.825 & 39.0144 & 118.872 \\
\hline 62 & -106.07 & 51.2064 & 118.872 \\
\hline 63 & -146.304 & 73.152 & 118.872 \\
\hline 64 & -134.112 & 80.4672 & 118.872 \\
\hline 65 & 130.454 & 51.2064 & 158.496 \\
\hline 66 & 126.797 & 56.0832 & 158.496 \\
\hline 67 & 90.208 & 24.384 & 158.496 \\
\hline 68 & 87.7824 & 30.48 & 158.496 \\
\hline 69 & 47.5488 & 6.096 & 158.496 \\
\hline 70 & 45.1104 & 13.4112 & 158.496 \\
\hline 71 & 0 & 0 & 158.496 \\
\hline 72 & 0 & 7.3152 & 158.496 \\
\hline 73 & -54.864 & 9.7536 & 158.496 \\
\hline 74 & -51.2064 & 14.6304 & 158.496 \\
\hline 75 & -103.632 & 31.6992 & 158.496 \\
\hline 76 & -98.7552 & 37.7952 & 158.496 \\
\hline 77 & -146.304 & 64.008 & 158.496 \\
\hline 78 & -141.427 & 70.7136 & 158.496 \\
\hline 79 & -184.099 & 102.413 & 158.496 \\
\hline 80 & -178.003 & 107.29 & 158.496 \\
\hline
\end{tabular}

was generated in ANSYS.

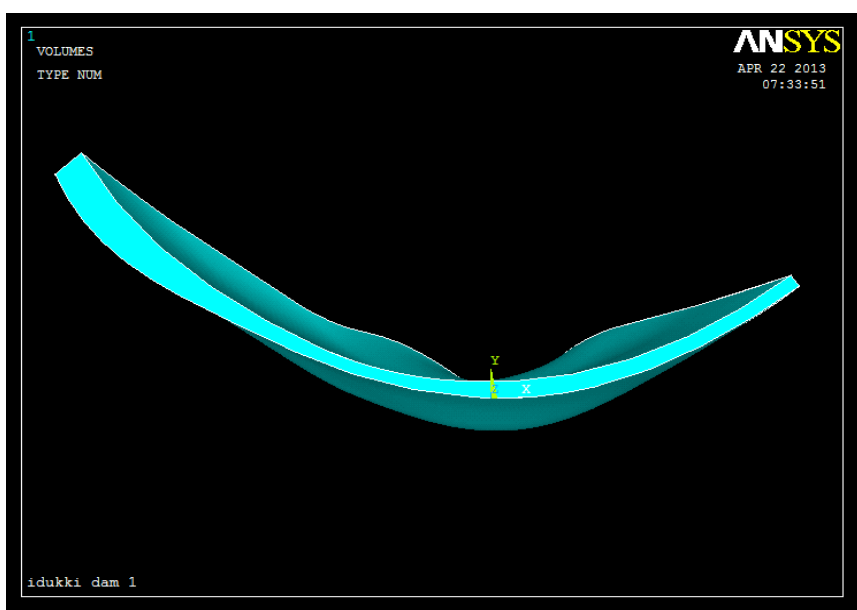

Fig 2.2 Dam model

Next step was the meshing of the model. Meshing was done using solid shell element as shown in the figure below, with four layers along the thickness of the dam.

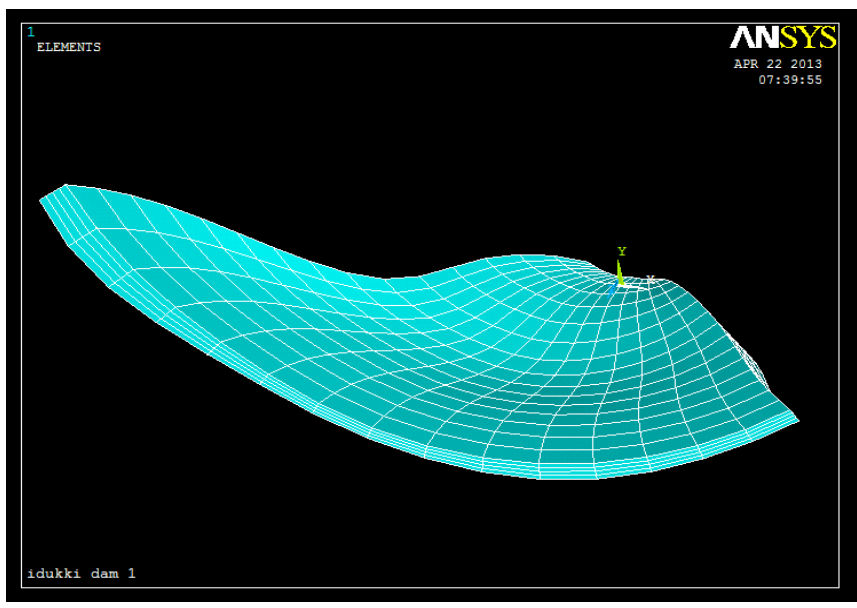

Fig 2.3 Mesh model

After meshing, 1280 nodes were obtained as shown in figure below.

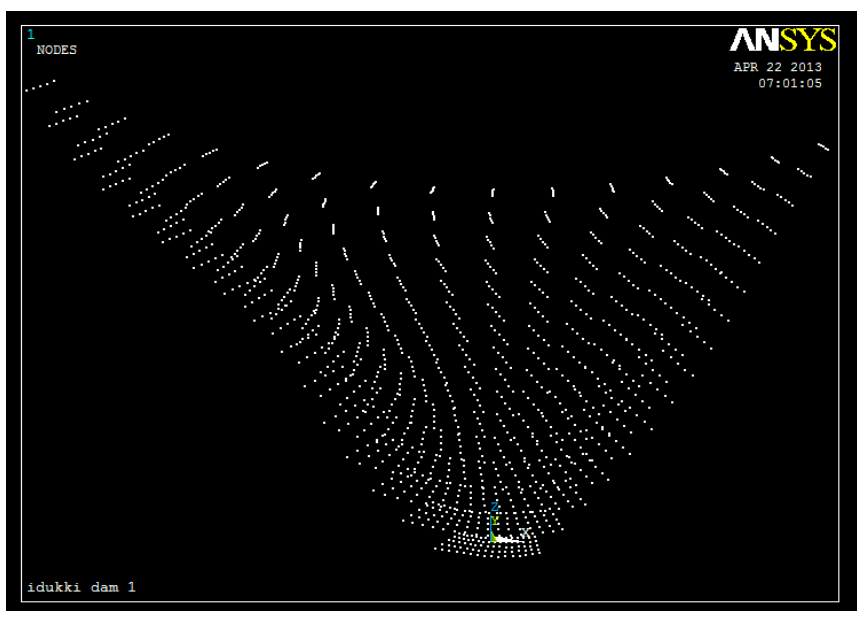

Fig 2.4 Nodes of the dam

Using the global coordinates the solid model of the arch dam

\section{ANALYSIS}




\subsection{Analysis for Various Load Cases}

Arch dams are subjected to various loads. Loads can be categorized into 2 basic types, static and dynamic. Static loads are sustained loads that do not change, or change very slowly compared to the natural periods of vibration of the structure. A dam's response to static loads is governed by its stiffness. Examples of static loads include dead load, hydraulic load from normal or flood conditions, forces from flowing water changing direction, uplift, forces from ice expansion, and internal stresses caused by temperature changes. Dynamic loads are transitory in nature. They are typically seconds or less in duration. Because of the speed at which they act, the inertial and damping characteristics of the dam as well as its stiffness affect the dam's behaviour. Examples of dynamic loads include earthquake-induced forces, blast-induced forces, fluttering nappe forces, or forces caused by the impact of ice, debris, or boats.

The various load combinations considered for the analysis are:

- Dead load only

- Dead load + Max Reservoir Level

- Dead load + Min Reservoir Level

- Dead load + Max Reservoir Level + Silt Pressure

- Dead load + Min Reservoir Level + Silt Pressure

\subsubsection{Dead Load Only}

Modulus of elasticity $=2.1 \times 10^{7} \mathrm{kN} / \mathrm{m}^{2}$

Poisson's ratio $=0.20$

Unit weight of dam material $=24 \mathrm{kN} / \mathrm{m}^{3}$

Considering the above mentioned details, analysis was conducted considering the self-weight of the dam only and the corresponding nodal displacements, stress intensities and stress resultants were obtained. The obtained results may be plotted as shown in figures respectively. The maximum values of displacements and their corresponding node points are tabulated Table 4.1 below.

Table 3.1 Maximum absolute value of nodal displacements

\begin{tabular}{|l|l|l|l|l|}
\hline & UX & UY & UZ & USUM \\
\hline NODE & 12 & 11 & 14 & 12 \\
\hline VALUE & 2.4382 & 4.5871 & 0.91394 & 5.1249 \\
\hline
\end{tabular}

Fig 3.1 shows the variation of displacement decreasing from the crest level to the abutments of the dam.

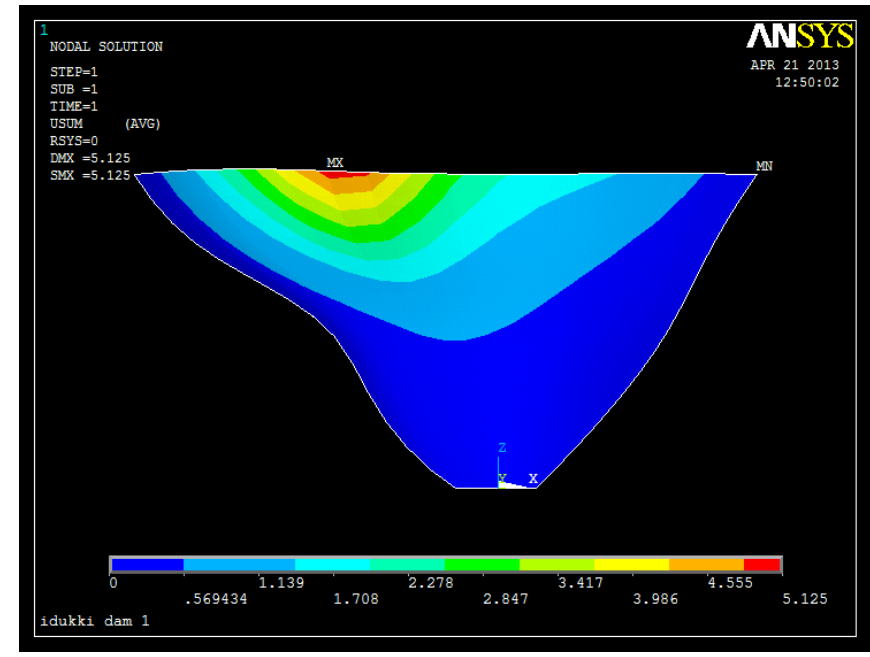

Fig 3.1 Nodal displacement of Dam

The maximum displacements are found to be occurring at top crest level and it is found to decrease to a minimum towards the abutments which are assumed to fix. The maximum and minimum values of stress intensities and stress equivalents and their corresponding node points are tabulated as Table 4.2 below.

Table 3.2 Stress intensity and von Mises stress at nod node.

\begin{tabular}{|c|c|c|c|c|c|}
\hline & $\mathrm{S} 1$ & $\mathrm{~S} 2$ & S3 & SINT & SEQV \\
\hline \multicolumn{6}{|c|}{ MINIMUM VALUE } \\
\hline Node & 258 & 17 & 11 & 84 & 84 \\
\hline Value & -63.73 & -74.200 & -454.30 & 0.9851 & 0.8604 \\
\hline \multicolumn{6}{|c|}{ Maximum value } \\
\hline Node & 238 & 111 & 111 & 11 & 11 \\
\hline Value & 104.22 & 14.518 & 12.741 & 463.97 & 446.57 \\
\hline
\end{tabular}

Fig 3.2 shows the displacement of the dam from its original shape at dead load only condition.

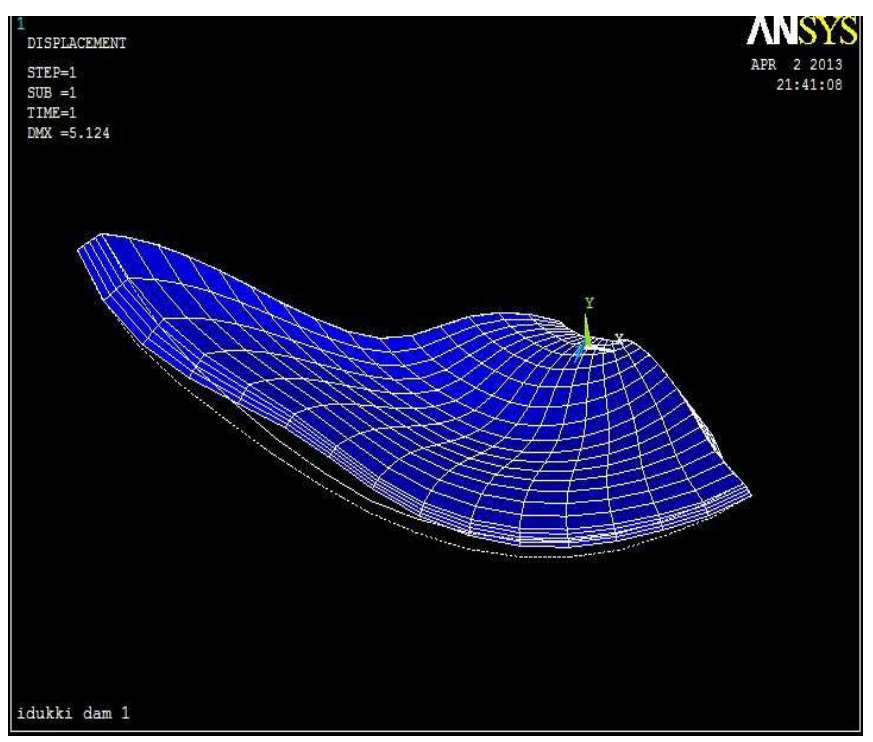

Fig 3.2 Displacement of the Dam 
Fig 3.3 shows the variation of stress intensity of the dam decreasing from the crest level to the abutments of the dam.

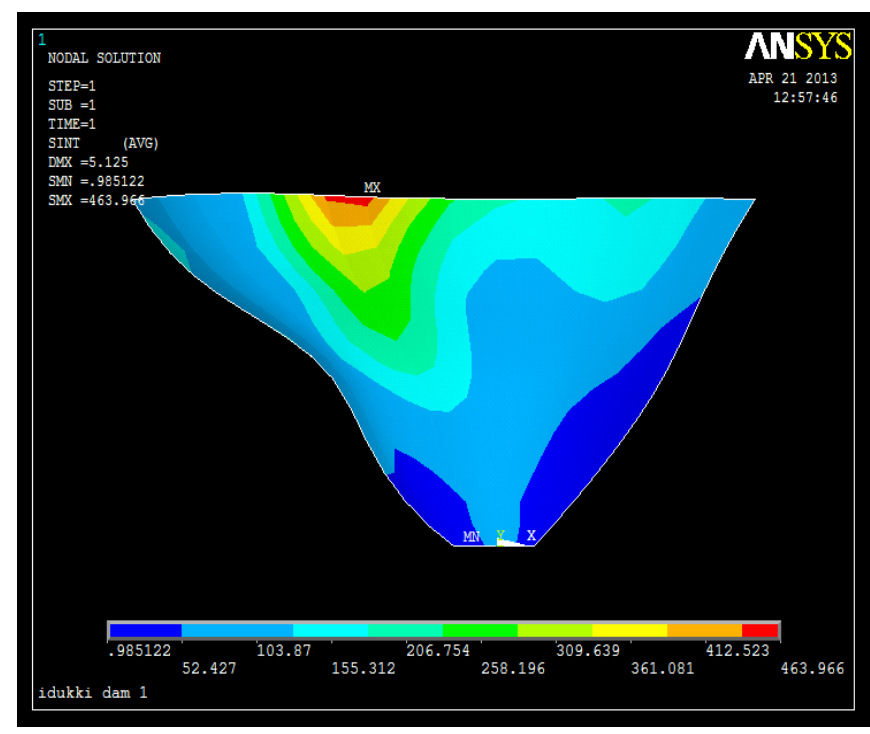

Fig 3.3 Stress intensity of the dam

Fig 3.4 shows the variation of von Mise stress of the dam decreasing from the crest level to the abutments of the dam.

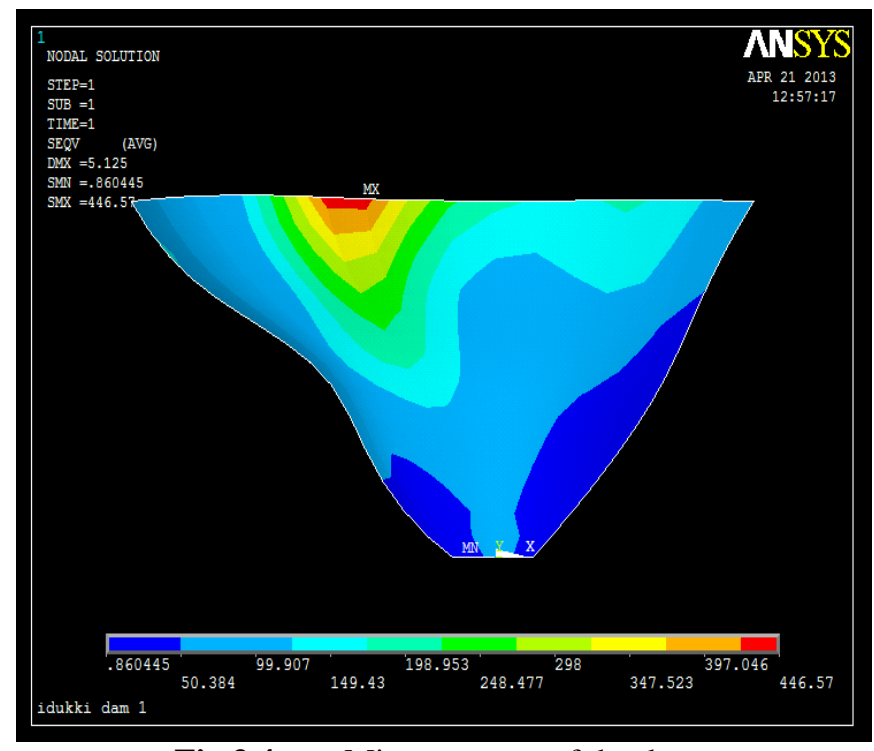

Fig 3.4 von Mises stresses of the dam

\subsubsection{Dead Load + Maximum Reservoir Level}

Unit weight of dam material $=24 \mathrm{kN} / \mathrm{m}^{3}$

Max reservoir level $=156.50 \mathrm{~m}$

Considering the above mentioned details, analysis was conducted considering the self-weight of the dam and maximum reservoir level and the corresponding nodal displacements, stress intensities and stress resultants were obtained. The obtained results may be plotted as shown in figures below respectively. The maximum values of displacements and their corresponding node points are tabulated below as Table 3.3.
Table 3.3: Maximum absolute value of nodal displacements

\begin{tabular}{|l|l|l|l|l|}
\hline & UX & UY & UZ & USUM \\
\hline NODE & 13 & 12 & 14 & 13 \\
\hline VALUE & -145.49 & -181.88 & -65.930 & 232.65 \\
\hline
\end{tabular}

Fig 3.5 shows the variation of displacement decreasing from the crest level to the abutments of the dam.

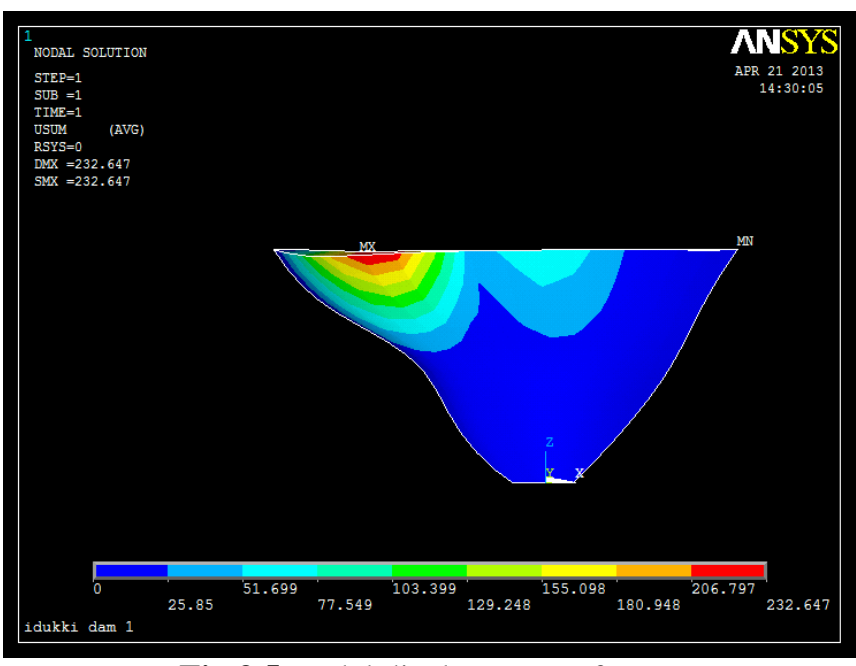

Fig 3.5 Nodal displacement of Dam

The maximum displacements are found to be occurring at a portion towards the left of crest level.

The maximum and minimum values of stress intensities and stress equivalents and their corresponding node points are tabulated as Table 3.4 below.

Table 3.4. Stress intensity and von Mises stress at nodes

\begin{tabular}{|l|l|l|l|l|l|}
\hline & S1 & S2 & S3 & Sint & Seqv \\
\hline Minimum value \\
\hline Node & 32 & 653 & 243 & 86 & 86 \\
\hline Value & -407.35 & -2429.2 & -15107 & 42.538 & 37.581 \\
\hline Maximum value \\
\hline Node & 17 & 258 & 258 & 17 & 17 \\
\hline Value & 22180 & 4786.4 & 3412.7 & 20002 & 18859 \\
\hline
\end{tabular}

Fig 3.6 shows the variation of stress intensity of the dam from the crest level to the abutments of the dam. 


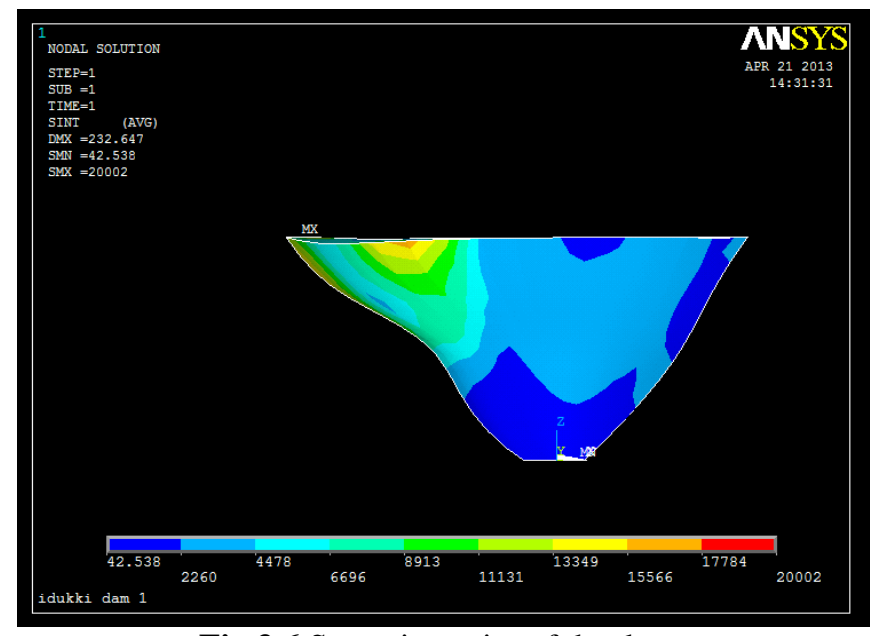

Fig 3.6 Stress intensity of the dam

The maximum value of stress intensities are found to be occurring at a portion towards the left of crest level.

Fig 3.7 shows the variation of von Mises stress of the dam from the crest level to the abutments of the dam.

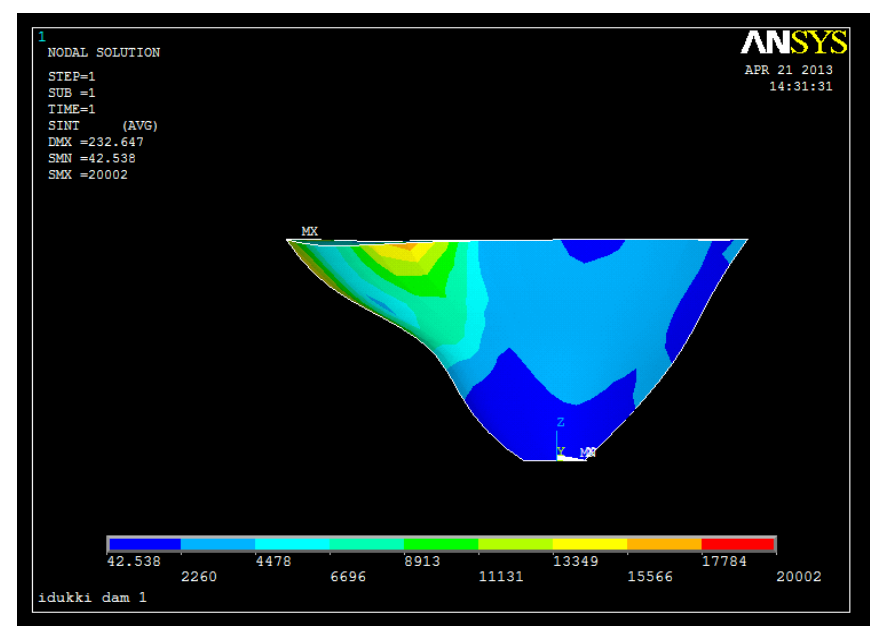

Fig 3.7 Stress intensity of the dam

The maximum value of von Mises stresses are found to be occurring at a portion towards the left of crest level.

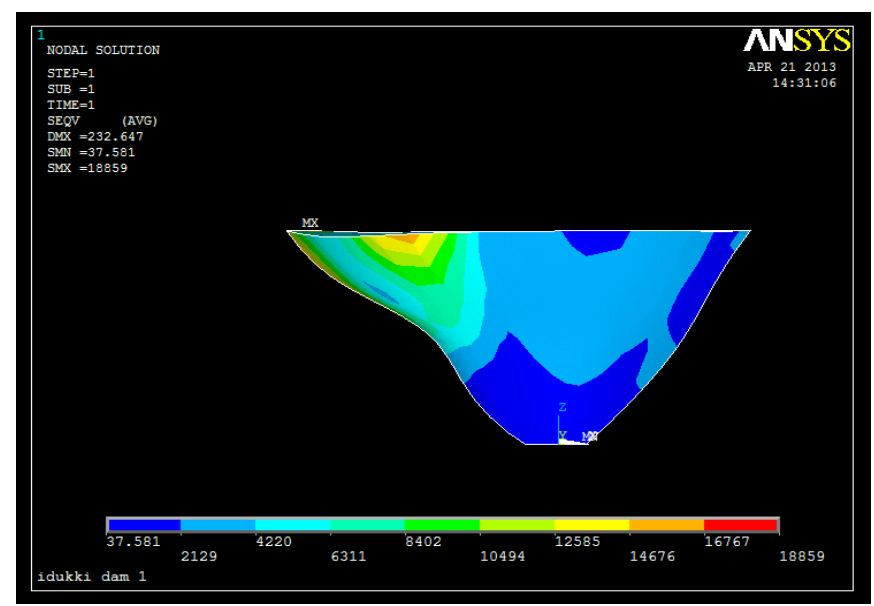

Fig 3.8 von Mises stresses of the dam

\subsubsection{Dead Load + Minimum Reservoir Level}

Unit weight of dam material $=24 \mathrm{kN} / \mathrm{m}^{3}$

Min reservoir level $=140 \mathrm{~m}$

Considering the above mentioned details, analysis was conducted considering the self-weight of the dam only and the corresponding nodal displacements, stress intensities and stress resultants were obtained. The obtained results may be plotted as shown in figures respectively. The maximum values of displacements, stress intensities and stress resultants and their corresponding node points are tabulated below.

Table 3.5 Maximum absolute value of nodal displacements

\begin{tabular}{|l|l|l|l|l|}
\hline & Ux & Uy & Uz & Usum \\
\hline Node & 31 & 32 & 13 & 13 \\
\hline Value & $0.621 \times 10^{-3}$ & $0.694 \times 10^{-3}$ & $0.72 \times 10^{-3}$ & $0.117 \times 10^{-3}$ \\
\hline
\end{tabular}

Fig 3.9shows the variation of displacement of the dam from the crest level to the abutments of the dam.

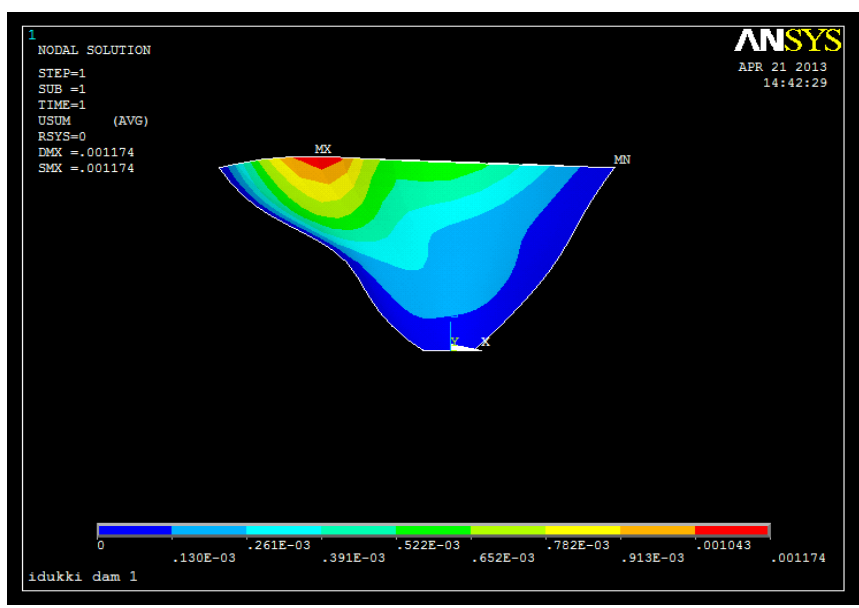

Fig 3.9 Nodal displacement of Dam

The maximum values of displacements are found to be occurring at top crest level and it is found to decrease to a minimum towards the abutments which are assumed to fix.

The maximum and minimum values of stress intensities and stress equivalents and their corresponding node points are tabulated as Table 3.6 below.

Table 3.6 Stress intensity and von Mises stress at nodes

\begin{tabular}{|l|l|l|l|l|l|}
\hline & S1 & S2 & S3 & Sint & Seqv \\
\hline \multicolumn{5}{|l|}{ Minimum value } \\
\hline Node & 17 & 17 & 17 & 56 & 56 \\
\hline Value & -0.0227 & -0.0284 & 0.148 & 0.00332 & 0.00313 \\
\hline Maximum value \\
\hline Node & 241 & 111 & 127 & 240 & 240 \\
\hline Value & 0.166 & 0.0280 & 0.0259 & 0.191 & 0.174 \\
\hline
\end{tabular}

Fig 3.10 shows the variation of stress intensity of the dam from the crest level to the abutments of the dam. 


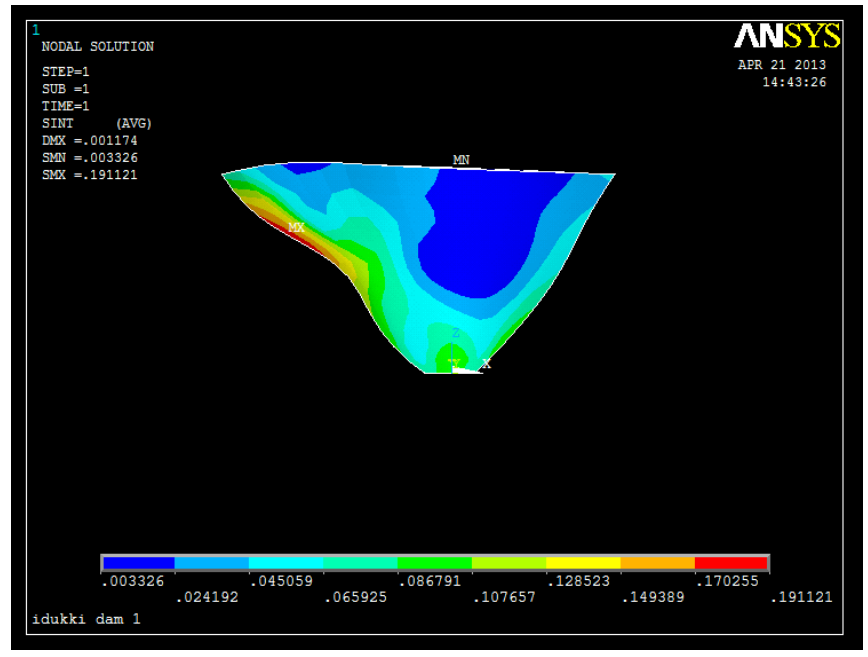

Fig 3.10 Stress intensity of the dam

The maximum value of stress intensities are observed to be occurring nearer to the left abutment of the dam and are found to be more towards the mid portion. The maximum values of von Mises stresses are observed to be occurring nearer to the left abutment of the dam and are found to be more towards the mid portion.

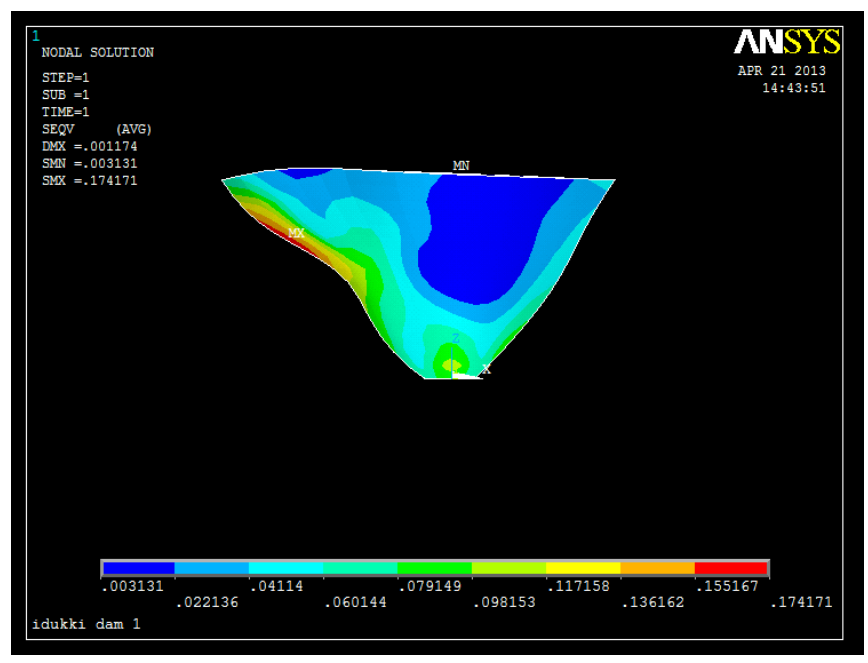

Fig 3.11 von Mises stresses of the dam

\subsubsection{Dead Load + Maximum Reservoir Level + Silt}

\section{Pressure}

Unit weight of dam material $=24 \mathrm{kN} / \mathrm{m}^{3}$

Max reservoir level $=156.5 \mathrm{~m}$

Height of silt level $=77.56 \mathrm{~m}$

Unit weight of silt $=12.5 \mathrm{kN} / \mathrm{m}^{3}$

Considering the above mentioned details, analysis was conducted considering the self-weight of the dam only and the corresponding nodal displacements, stress intensities and stress resultants were obtained. The obtained results may be plotted as shown in figures respectively. The maximum values of displacements, stress intensities and stress resultants and their corresponding node points are tabulated below.
Table 3.7 Maximum absolute value of nodal displacements

\begin{tabular}{|l|l|l|l|l|}
\hline & UX & UY & UZ & USUM \\
\hline NODE & 12 & 11 & 14 & 12 \\
\hline VALUE & -2.3908 & -4.4994 & -0.89521 & 5.0258 \\
\hline
\end{tabular}

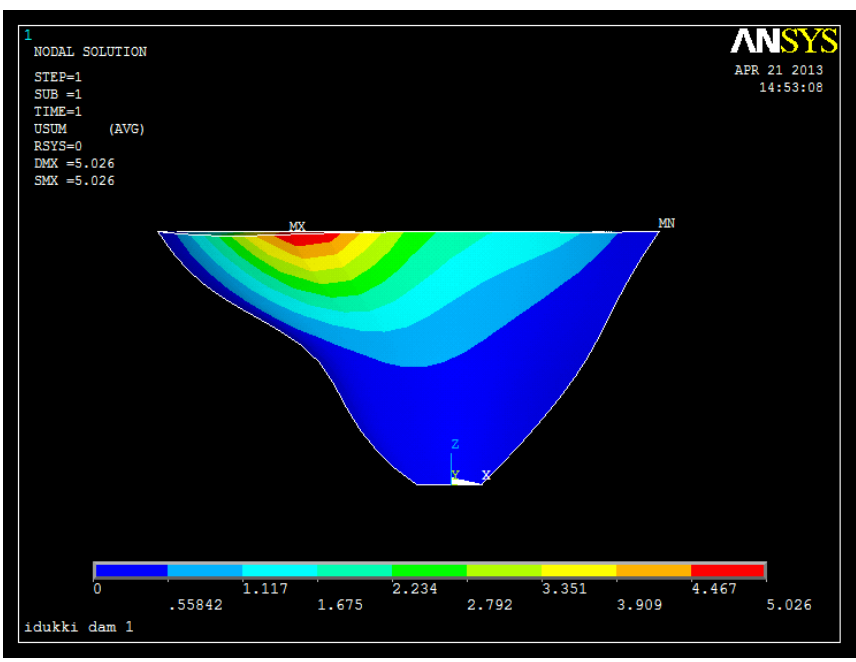

Fig3.12. Nodal displacement of Dam

The maximum value of displacements are found to be occurring at top crest level and it is found to decrease to a minimum towards the abutments which are assumed to fixed.

Table3.8. stress intensity and von Mises stress at nodes

\begin{tabular}{|l|l|l|l|l|l|}
\hline \multicolumn{7}{|l|}{} & S1 & S2 & S3 & SINT & SEQV \\
\hline \multicolumn{5}{|l|}{ Minimum value } \\
\hline Node & 111 & 111 & 238 & 84 & 84 \\
\hline Value & -12.437 & 14.189 & 101.98 & 0.90315 & 0.81114 \\
\hline \multicolumn{5}{|l|}{ Maximum value } \\
\hline Node & 11 & 17 & 258 & 11 & 11 \\
\hline Value & 445.67 & 72.732 & 62.478 & 455.12 & 438.08 \\
\hline
\end{tabular}

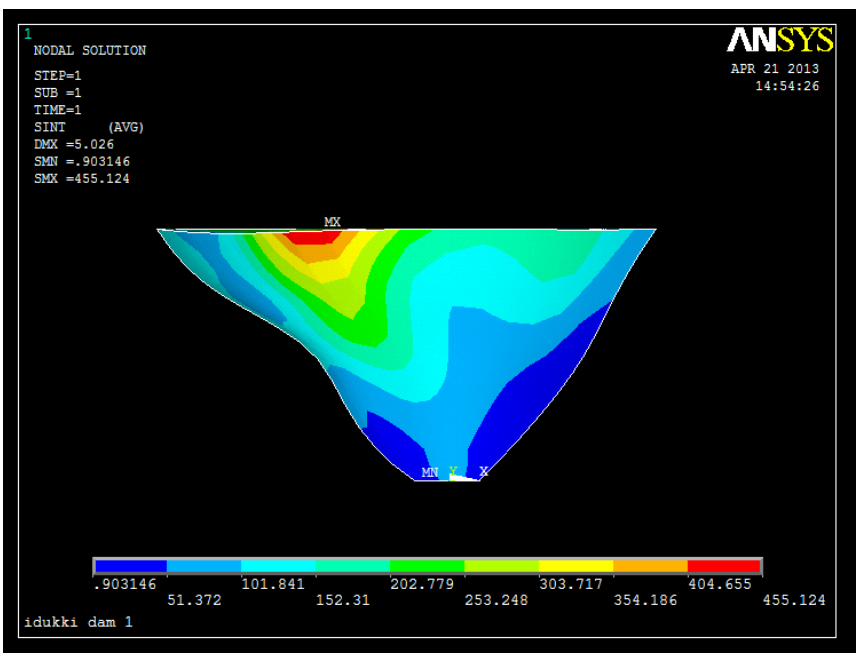

Fig 3.13 Stress intensity of the dam

The maximum value of stress intensities are found to be occurring at top crest level and it is found to decrease to a minimum towards the abutments which are assumed to fixed. 


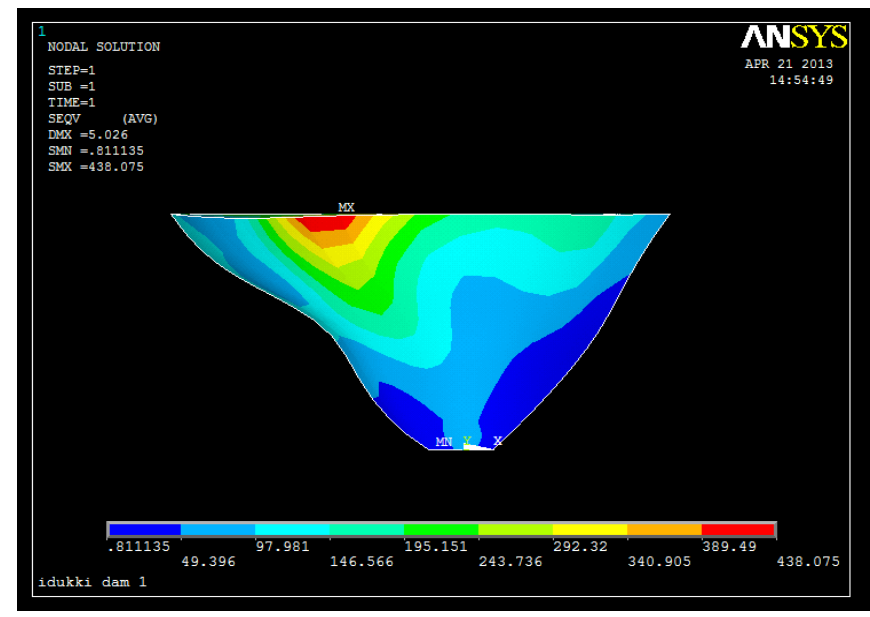

Fig 3.14 Von Mises stresses of the dam

The maximum value of von Mises stress are found to be occurring at top crest level and it is found to decrease to a minimum towards the abutments which are assumed to fixed.

\subsubsection{Dead Load + Minimum Reservoir Level + Silt}

\section{Pressure}

Unit weight of dam material $=24 \mathrm{kN} / \mathrm{m}^{3}$

Min reservoir level $=140 \mathrm{~m}$

Height of silt level $=77.56 \mathrm{~m}$

Unit weight of silt $=12.5 \mathrm{kN} / \mathrm{m}^{3}$

Considering the above mentioned details, analysis was conducted considering the self-weight of the dam only and the corresponding nodal displacements, stress intensities and stress resultants were obtained. The obtained results may be plotted as shown in figures respectively. The maximum values of displacements, stress intensities and stress resultants and their corresponding node points are tabulated below.

Table 3.9 Maximum absolute value of nodal displacements

\begin{tabular}{|l|l|l|l|l|}
\hline & UX & UY & UZ & USUM \\
\hline Node & 31 & 32 & 13 & 13 \\
\hline Value & 0.621 & $0.694 \times 10^{-3}$ & $0.7201 \times 10^{-3}$ & 0.11735 \\
\hline
\end{tabular}

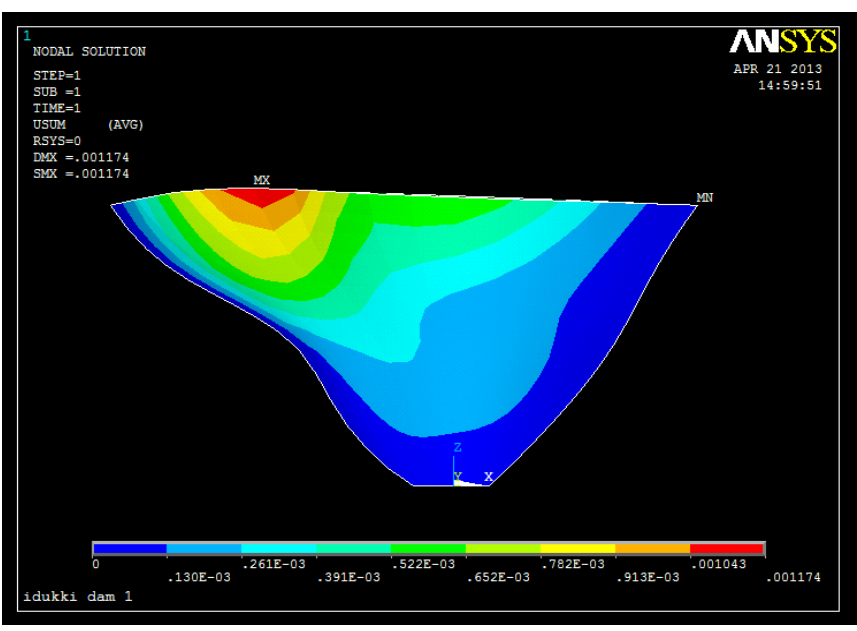

Fig 15 Nodal displacement of Dam
The maximum values of displacements are found to be occurring at top crest level and it is found to decrease to a minimum towards the abutments which are assumed to fixed.

Table 3.10 Stress intensity and von Mises stress at nodes

\begin{tabular}{|l|l|l|l|l|l|}
\hline & S1 & S2 & S3 & SINT & SEQV \\
\hline Minimum value \\
\hline Node & 18 & 18 & 18 & 58 & 58 \\
\hline Value & -0.9633 & -0.793 & 0.9539 & 0.0033 & 0.0031 \\
\hline Maximum value \\
\hline Node & 245 & 111 & 132 & 240 & 240 \\
\hline Value & 0.8083 & 0.9437 & 0.1051 & 0.1911 & 0.1741 \\
\hline
\end{tabular}

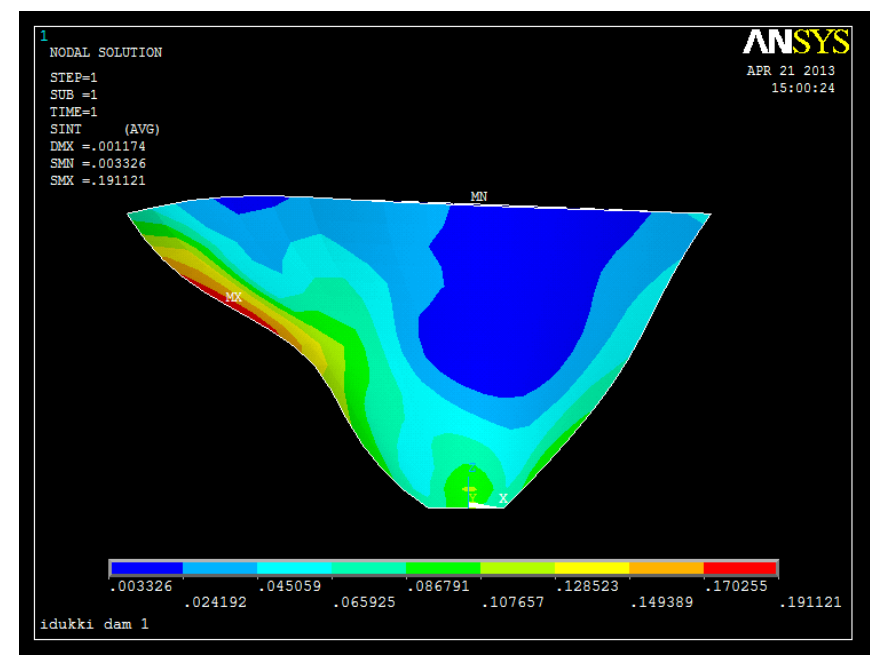

Fig 16 stress intensity of the dam

The maximum values of stress intensity are observed to be occurring nearer to the left abutment of the dam and are found to be more towards the mid portion.

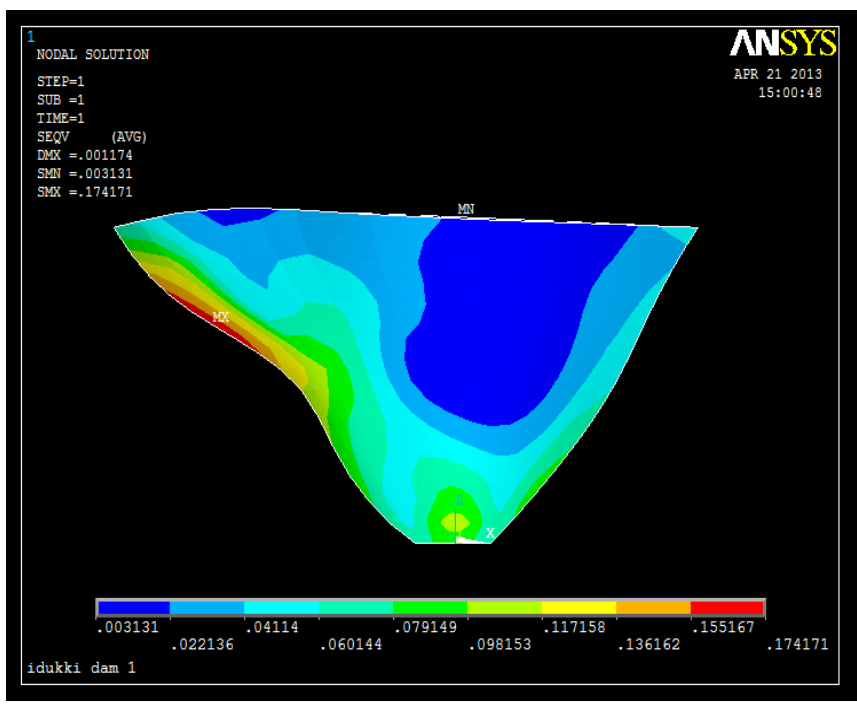

Fig 3.17 von Mises stresses of the dam

The maximum values of von Mises stresses are observed to be occurring nearer to the left abutment of the dam and are found to be more towards the mid portion. 


\section{CONCLUSIONS}

- The analytical definitions of arch dam were collected from KSEB, and a C program was made, which generated the Global $\mathrm{X}, \mathrm{Y}$ and $\mathrm{Z}$ coordinates of arch dam.

- From the analysis it has been found that for various load conditions, the obtained values of stress and deflection is within the permissible limit and hence, the dam is safe.

- From the results obtained from the analysis, it can be observed that the maximum values of displacement, stress intensity and von Mises stress seems to occur at a portion towards the left side of the crest level of the dam. This may be due to the presence of lesser value of thickness at this portion.

- The thickness at various section of dam is a function of depth (elevation). The thickness of the dam can be further reduced at the portions where stress intensities were found to be minimum.

- The maximum deformation/deflection for various load combinations are :

- Dead load only - $5.124 \mathrm{~mm}$ at node 12, left bank

- Dead load + Max Reservoir Level - 232.65 mm at node13, left bank

- $\quad$ Dead load + Min Reservoir Level - 0.001174 $\mathrm{mm}$ at node 12 , left bank

- Dead load + Max Reservoir Level - $5.028 \mathrm{~mm}$ at node 12, left bank + Silt Pressure

- $\quad$ Dead load + Min Reservoir Level - 0.001174 $\mathrm{mm}$ at node 13, left bank + Silt Pressure

- From Table-5 it was observed that the displacement was found to be maximum at node 13 in the left bank of dam for Dead load + Max Reservoir Level.

- From Table-5 it was observed that the maximum stress intensity was found to be at node 17 , left bank of the dam.

- All the stresses obtained were found to be within the permissible limit of stresses.

\section{SCOPE FOR FUTURE STUDY}

Further studies can be conducted neglecting various assumptions made in the initial stage of this paper. Analysis can be done taking care of various soil conditions. Also inspection galleries can be considered for analysis of later stage. Uplift pressure due to piping action can also be considered for further analysis and studies. The wind effect can also make significant changes in the stress values. Therefore after obtaining the wind data of the region, the wind effect can also be incorporated in the analysis.

\section{REFERENCES}

[1] Theoretical manual for analysis arch dams by Department of army, US army corps of engineers

[2] Engineering guidelines for the evaluation of hydropower projects by Federal

[3] Energy Regulatory Commission (FERC).
[4] C S Krishnamoorthy, Finite Element Analysis Theory and Programming, Tata McGraw-Hill Publishing Company Ltd

[5] Victor Saouma, Eric Hansen, Balaji Rajagopalan, Statistical and 3D nonlinear finite element analysis of Schlegeis dam, Dept. of Civil Engineering, University of Colorado, Boulder 